\title{
“NOSSO UMBIGO TÁ ENTERRADO AQUI": MEMÓRIA E TRABALHO EM UMA FÁBRICA DE PORCELANAS DE PORTO ALEGRE
}

\author{
Carolina Dalla Chiesa ${ }^{1}$ \\ Neusa Rolita Cavedon ${ }^{2}$
}

\section{Introdução}

Este trabalho é fruto das reflexões tecidas no âmbito da disciplina que realizei no Programa de Antropologia Social da UFRGS - Individualismo, Sociabilidade e Memória - e que me levaram a buscar compreender as relações entre memória e trabalho à luz das narrativas biográficas que emergem em um locus específico: uma empresa de porcelanas que vive um momento ímpar de sua história, qual seja, seu processo de fechamento. Alguns dos questionamentos que nortearam as aproximações e entrevistas que realizei em campo podem ser colocados da seguinte forma: Como este momento atual é trabalhado pelas pessoas que fazem parte deste lugar? Que memórias são narradas ali, a que fazem referência e o que revelam sobre o cotidiano do trabalho e suas transformações?

Tais questionamentos estão direcionados à Rebis Indústria e Comércio de Porcelanas, localizada no bairro Vila Jardim, na cidade de Porto Alegre, no estado do Rio Grande do Sul. Fundada em 1956, sua principal produção são peças decorativas de porcelana - ou como tratadas por seus donos, "as estatuetas" - entre outros produtos que fazem parte de sua história. A empresa que teve ao longo de sua história um total aproximado de duzentos funcionários, hoje conta apenas com seus dois sócios, Sérgio e Marcos - respectivamente, tio e sobrinho - e Dona Eva, ex-funcionária aposentada que ainda realiza trabalhos manuais específicos na produção das peças, como a pintura.

As atividades desta empresa estão sendo encerradas atualmente. Entretanto, a produção de estatuetas ainda está em funcionamento, o que mostra um desejo de continuar, de permanecer no espaço de trabalho e de não perder o vínculo com aquilo que se constitui um convívio familiar, uma forma de sociabilidade (Simmel, 2006), um estilo de vida (Schutz, 2012) que são parte da realidade de uma sociedade complexa

\footnotetext{
${ }^{1}$ Universidade Federal do Rio Grande do Sul, Brasil.

${ }^{2}$ Universidade Federal do Rio Grande do Sul, Brasil.
} 
moderno-contemporânea (Velho, 2003) e, portanto, sofrem transformações ao longo do tempo.

As discussões acerca da memória do trabalho trazidas neste artigo enfocam as narrativas das pessoas acima citadas que aconteceram em entrevistas ${ }^{3}$ e diversas visitas feitas em campo para conhecer o local de trabalho da Rebis e as pessoas que fazem parte deste espaço. Assim, o artigo está estruturado de modo a trazer as falas dos sujeitos e reflexões sobre suas memórias considerando seus entendimentos sobre o passado e projetos futuros daqueles que fazem parte da história dessa empresa, tendo em vista seus cruzamentos com a própria trajetória das estatuetas de porcelana, bem como o papel da família como um quadro de referência (Halbwachs, 2006) presente nas escolhas dos indivíduos.

Como forma de introduzir alguns direcionamentos da análise, cabe mencionar que as memórias narradas são profundamente marcadas por aspectos da materialidade dos objetos com os quais os sujeitos trabalharam ao longo da história da empresa. Assim, as referências às noções de trajetória social das coisas (Appadurai, 1986) e objetos biográficos (Hoskins, 1998; Bosi, 1994), juntamente aos outros referenciais, são importantes para "ler" as narrativas como momentos que em que a memória é construída (Lins de Barros, 2011).

\section{Conhecendo a Rebis}

Conheci a Rebis, juntamente com minha orientadora de mestrado, por meio de um encarte publicitário denominado Porto Alegre Quem Diria (2013), que mostra estabelecimentos comerciais peculiares da cidade, entre eles o que hoje é a única fábrica de estatuetas de porcelana em funcionamento no Brasil. Entrei em contato por telefone com Marcos - sócio e administrador, 45 anos - e comecei a fazer visitas à Rebis inicialmente acompanhada de minha orientadora - até culminar com as entrevistas realizadas em Janeiro, Fevereiro e Junho de 2013.

Localizada no bairro Vila Jardim, a Rebis situa-se em um prédio de esquina em uma área residencial que, porém, é cercada por outros estabelecimentos comerciais. Ao

\footnotetext{
${ }^{3}$ Trata-se de entrevistas em profundidade realizadas no primeiro semestre de do ano de 2013. As visitas, por sua vez, foram registradas em diários de campo.
} 
adentrar no prédio, cujo primeiro espaço é um escritório, noto as recordações de um "tempo de auge 4 ", quando a empresa vendia as estatuetas de porcelana por todo o Brasil. Uma estante guarda as "marcas do passado" (Ricoeur, 2012) com diversas peças que revelam diferentes estágios da Rebis, juntamente das fotografias, que são os primeiros registros mostrados por Sérgio ${ }^{5}$ quando se adentra no espaço da empresa. Com estes registros, estão outras fotografias no escritório que revelam o importante papel da família na construção do negócio e nas escolhas dos indivíduos como um campo de possibilidades (Velho, 2003) que será explorado mais adiante.

As visitas realizadas eram pautadas por perguntas de nossa parte em relação à Rebis com a intenção de entender o que estava acontecendo no atual momento, uma vez que, por telefone, soubemos que a fábrica estava em processo de fechamento. Entre diversas outras histórias contadas, a materialidade da produção das estatuetas também passa a ganhar relevância em suas narrativas a partir dessas visitas, no momento em que nós, interlocutoras, adquirimos algumas de suas estatuetas. Por parte deles, as compras eram incentivadas também porque nos diziam que a intenção atual era finalizar com o estoque de estatuetas de porcelana. De certo modo, as visitas seguintes foram condicionadas pelas iniciais uma vez que meu contato era maior com Marcos, o que implicitamente se dava por uma questão etária, ao contrário da relação que travei com Sérgio.

Cito um trecho de minhas anotações em uma das visitas feitas à fábrica: "Entrando na fábrica, encontro um espaço marcado pelo tempo, repleto de estantes de madeira com estatuetas - o que deixa o ambiente mais escuro - algumas mais antigas que outras e uma mesa retangular onde hoje o trabalho é realizado por Dona Eva ${ }^{6}$. "Essa aqui, por exemplo, tá há 15 anos aqui parada" - diz Marcos a mim referindo-se a uma estatueta específica enquanto caminhávamos para conhecer os espaços da fábrica. Ele leva-me aos fornos antigos, à sala das matrizes $^{7}$, ao local de produção da massa de porcelana e, por fim, retornamos à mesa central onde Dona Eva continua pintando as estatuetas e preparando as tintas enquanto conversamos. Ao lado dela, um relógio ponto

\footnotetext{
${ }^{4}$ Indicações semelhantes de "tempos" de acordo com a trajetória de uma comunidade de mineiros na França, estão descritas em Eckert (2012).

${ }^{5}$ Sérgio é sócio e tio de Marcos, hoje com 79 anos.

${ }^{6}$ Dona Eva, aposentada, ex-funcionária responsável por pintar as estatuetas de porcelana.

${ }^{7}$ Matrizes são as formas com as quais se molda a massa de porcelana para produzir as estatuetas.
} 
marca o tempo que antes servia como controle para horários de entrada e saída de funcionários, os quais faziam parte de uma rígida rotina de trabalho dividida conforme os espaços da fábrica".

As estatuetas traçam percursos na fábrica desde o início de seu processo de produção até seu fim, porém, esse percurso não se completa, pois, grande parte das estatuetas não sai da fábrica, sendo este um dos problemas que se vive hoje na Rebis. "Tá muito difícil, sabe? As pessoas não se interessam mais pelo que a gente produz" diz Sérgio em uma de minhas visitas.

Entretanto, a fábrica continua em funcionamento: peças continuam sendo produzidas, tentativas de vendas continuam sendo feitas e, apesar da sensação que tenho de um tempo que parou no espaço da fábrica, Sérgio e Marcos sempre buscavam dizer que estão com pressa e que não dispõem muito tempo, inclusive para as entrevistas. Cotidianamente, Sergio se instala em sua mesa onde busca fazer contatos com revendedores e possíveis clientes, enquanto que Marcos direciona-se à fábrica para produzir mais estatuetas ou consertar aquelas que estão quebradas. Dona Eva, por sua vez, comparece todos os dias para continuar as pinturas das estatuetas.

Cabe descrever, então, que tais estatuetas são peças de porcelana esmaltadas, em geral, medindo dez centímetros de comprimento ou mais - dependendo do modelo rendadas por um tecido chamado "filó", pintadas de cores como azul, rosa, verde e branco, sendo, em sua maioria, representações do gênero feminino. Algumas delas são denominadas "Bailarina", "Luis XV", "Espanhola" que, de acordo com seu tamanho, variam o tempo de produção, estimado em um dia inteiro ou mais.

Duas fotografias de catálogos disponibilizadas por Sérgio para mostrar parte de suas coleções estão colocadas adiante. Tais fotografias datam, aproximadamente, da década de 1970, sendo alguns de seus modelos inspirados em estatuetas fabricadas na Alemanha. 

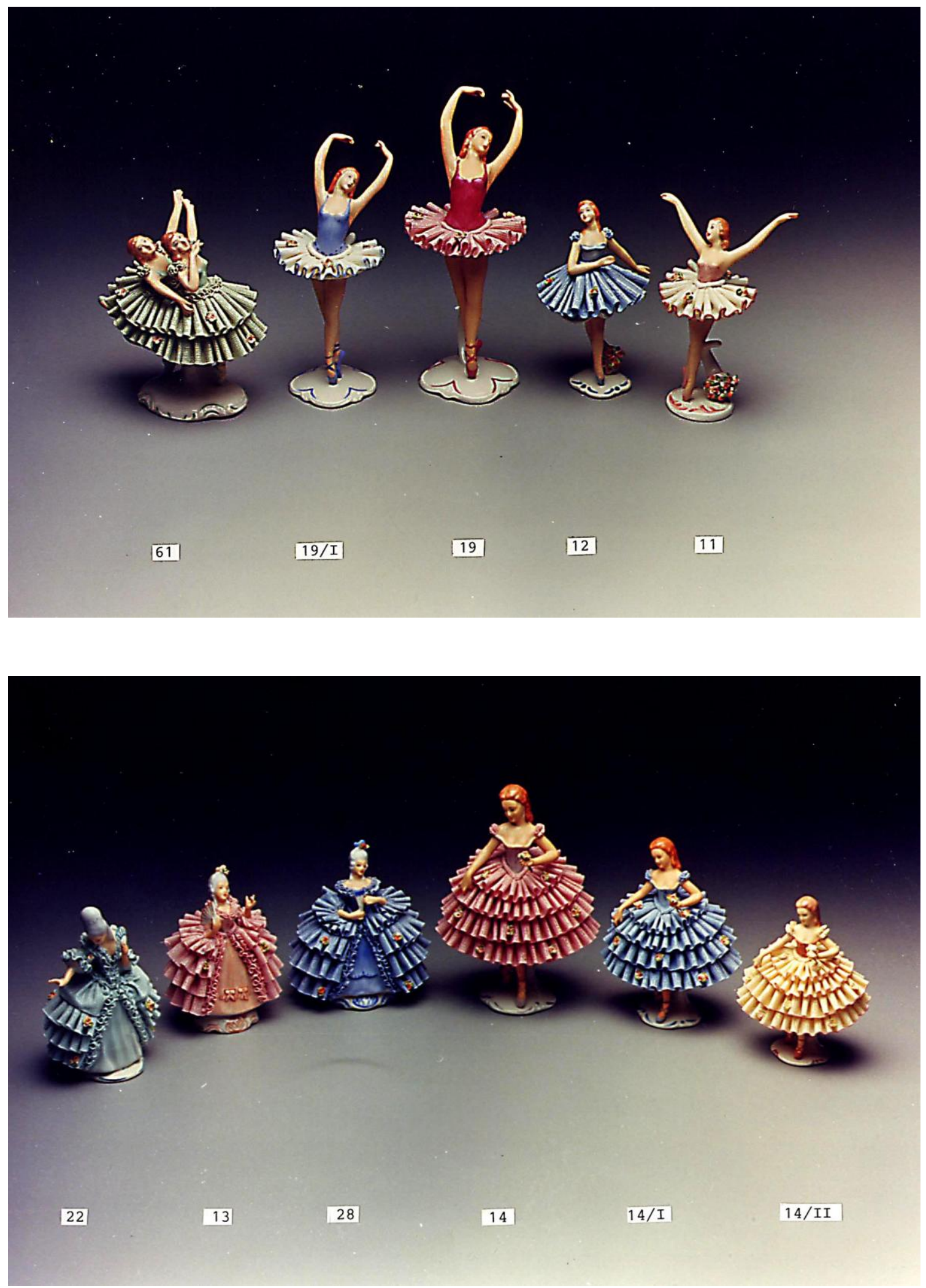
Trata-se de um trabalho que, na opinião de Dona Eva, requer muita paciência e delicadeza de modo que, qualquer pequeno erro invalida a peça por inteiro. Sendo assim, suas narrativas sobre trabalho são muitas vezes pontuadas pelas dificuldades que Sérgio, Marcos e Dona Eva viveram com a produção diária das estatuetas no prédio da fábrica.

"Só falta vender o prédio. Aí vamos guardar as estatuetas que sobrarem", fala Sérgio em entrevista. Na opinião tanto de Marcos quanto de Sérgio, o que os mantém ali diariamente, é a presença física da fábrica, que quando for vendida, dará fim à existência da Rebis.

\section{Narrativas do Trabalho: do início aos dias atuais}

Em todas as visitas feitas à Rebis, uma das características mais marcantes da interação com Sérgio e Marcos é a profusão de histórias contadas sobre diferentes períodos vivenciados na empresa. Histórias essas que são muitas vezes recontadas e revelam biografias intrinsecamente vinculadas ao cotidiano de trabalho uma fábrica que viveu um apogeu - período ao qual as memórias sempre fazem referência.

$\mathrm{Na}$ entrevista realizada com Sérgio, este explicou que sua entrada na empresa se deu por meio do convite de um dos sócios da Rebis em 1956, chamado Ivo que precisava de alguém que pudesse controlar a parte administrativa da empresa. Dois outros sócios também faziam parte da empresa, Steiner e José ${ }^{8}$, sendo que Steiner trouxera os moldes de porcelana da Renner ${ }^{9}$ e José cedera um pavilhão onde a fábrica funcionava até 1970, quando houve uma mudança de local.

Aí eu entrei e eu passei muito trabalho. Era concorrência do Renner, eu sem conhecimento. Então foi muito sacrifício, eu sem dinheiro. Aí depois de um ano eu pensei em ir embora, que é que eu vou fazer aqui? Isso aqui não dá em nada. Aí eu casei em maio, e pensei bá eu tenho que tomar uma atitude na minha vida. [...] Aí

\footnotetext{
${ }^{8}$ Os três sócios eram estrangeiros: Steiner era alemão, José era Polonês e Ivo era Iugoslavo. Cada um deles saiu da Rebis em momentos diferentes, pois tinham suas outras profissões e atividades, deixando apenas Sérgio como responsável pela fábrica.

${ }^{9}$ Sérgio referencia diversas vezes a empresa denominada Porcelanas Renner cuja importância diz respeito ao papel que ela teve dificultando o dia-a-dia do trabalho, uma vez que, ressalta ele, a Renner queria fazêlos entrar em falência.
} 
nesse ínterim eu já era sócio, porque eu disse que queria ir embora e eles me botaram de sócio. Dez por cento ${ }^{10}$.

Sérgio, a partir deste momento, trabalhando na Rebis, adquiriu confiança dos outros sócios e com a saída dos demais, tornou-se o sócio principal, juntamente com Ivo. Continuar na Rebis implicava assumir cada vez mais responsabilidades no trabalho da fábrica e enfrentar as dificuldades do dia a dia:

Guria, as renda começou a estragar, não dava renda. Chamei as guria, que é que vamos botar? O que não botamos? Que vamos fazer? Ah, seu Sérgio acho que tá faltando um pouco disso aqui elas diziam, aí nunca mais tive problema com a renda. Mas também tive problema com a renda porque onde eu comprava o filó, era muito fininho, ele quebrava, e aí a fábrica de filó fechou.

Homem não servia pra isso aí, homem é muito abrutalhado. E nunca tentei também. O seu Steiner quando ele foi embora, ele andou me dando umas dica. Em primeiro lugar era pra eu escolher uma mulher pra trabalhar. Sérgio, o senhor examina as unhas, tem que ser com as unhas bem feitinhas, esmalte clarinho, não bota mulher com aqueles esmalte colorido, porque não presta.

Cabe observar que o gênero é importante para o trabalho da fábrica na medida em que Sérgio entende que a mulher é mais apropriada para a colocação de renda e pintura que o homem. Marcos, em entrevista, comentou também que nunca tentou realizar essas tarefas, mas acredita que são apropriadas para as mulheres, enquanto que a produção da massa de porcelana ${ }^{11}$, carregamento de caixas e outros trabalhos "menos delicados" são próprios para o homem. Sendo assim, o savoir-faire é fortemente condicionado pelo gênero, dado que não há uma pessoa na Rebis que consiga fazer uma estatueta, do início ao fim em razão das divisões do trabalho.

No esforço de Sérgio, Marcos e Dona Eva de buscar contar-me suas memórias, o que ouço, na maior parte do tempo, é o relato do trabalho com estatuetas de porcelana. Este fato reitera algo que Hoskins (1998) viu quando de seu trabalho de campo: ao solicitar que as pessoas contassem suas vidas, o que elas narravam eram objetos e as histórias com os objetos. Do mesmo modo, na Rebis, o contar de histórias de vida é um contar e recontar de um trabalho com "objetos biográficos” (Hoskins, 1998). Assim,

\footnotetext{
${ }^{10} \mathrm{O}$ que começa a ficar visível já no início e se desenrola durante toda a entrevista é uma constante referência aos números, porcentagens, valores monetários como parte importante das memórias narradas tanto de Sérgio quanto de Marcos. Cabe observar que é possível que essa predominância se dê em razão de minha área ser a Administração, logo, as escolhas sobre o que falar e como falar podem estar condicionadas a quem os pergunta.

${ }^{11}$ Preparar a massa de porcelana é uma das etapas iniciais do processo de produção.
} 
entendendo que as coisas tem uma vida social (Appadurai, 1986), a vida e a trajetória das estatuetas cruzam-se com a vida e a trajetória das pessoas.

Além do trabalho e das dificuldades com os objetos, frequentemente, nos relatos de Marcos e Sérgio, despontam situações de negociação, de compra, de venda, de valores, quantidades de dinheiro envolvido na produção e venda das estatuetas, mesclados à enorme quantidade de trabalhos que eles realizavam. Contam-se histórias de representantes comerciais, de funcionários, de antiquários, de roubos na fábrica: todas elas, situações fragmentadas, pedaços da história do trabalho na empresa que não são contados linearmente. São fragmentos sobrepostos que contam e recontam de um tempo vivido e intercambiados no tempo narrado, como fala Benjamin (1985) sobre a faculdade de intercambiar e narrar experiências.

\begin{abstract}
Eu tinha uma firma, nunca me esqueço, Aqui Lar. Ele um dia telefonou pra mim porque eu não podia atender os pedido dele. As estatuetas tavam no auge. Aí ele perguntou pra mim, o senhor não quer ganhar dinheiro? Aí eu perguntei, mas porque seu Pilar? Não, porque eu to pedindo aqui meus pedido de cinco mil reais e o senhor vai me mandar mil reais. Eu disse, Seu Pilar eu tenho que despachar pra todos todos, eu tenho muito pedido. Aí ele disse, então, o senhor não quer ganhar dinheiro. E eu disse, que é isso, eu quero, quem não quer? É que a fabricação das minhas estatueta não é como fabricar pãozinho. Pra pegar um funcionário ele leva um ano pra aprender e começar a funcionar. E a mão de obra leva 5, 6, 7, 8, 9 horas pra fazer uma estatueta. Aquela 65 que é a espanhola, só pra colocar o tecido e aquela barrinha, leva 3 hora, Carol. [...] Quando eu já tava sozinho, eu era o técnico, controlava a produção por fichinhas, eu tinha fichinhas de cada funcionário por minuto. Tinha cálculo de cada peça por minuto, então, eu ia todo dia pra casa, porque eu não tinha tempo de controlar aqui na fábrica, então eu controlava o minuto de cada uma. Tinha de mil, mil e duzentos, mil e quatrocentos. E aquela que fazia acima de novecentos ganhava uma gratificação. Mas tinha que ser perfeito, porque se não botava um olho pra cima, outro pra baixo pra ganhar gratificação.
\end{abstract}

Para Simmel (2004), o valor é um julgamento de algo, não o valor da coisa em si uma vez que se refere às subjetividades atribuídas aos objetos. No âmbito das memórias de Sérgio, dizer o quanto vale uma estatueta, quanto tempo ela leva para ficar pronta e quanto tempo é necessário para ensinar uma pessoa a produzi-la é uma forma de classificar a estatueta - e, portanto, seu trabalho diário - como diferenciado em relação a outros tipos de trabalhos que, em sua concepção, demandam menos esforços.

Com o desenvolvimento da Rebis, Sérgio chamou seu sobrinho, Marcos, que entrou na fábrica com treze anos em 1982 para ajudar Sérgio e sua esposa com os trabalhos administrativos. Porém, Marcos deixa claro que "fazia de tudo um pouco" 
junto com seu tio. Suas memórias, da mesma forma, estão enraizadas no cotidiano do trabalho na fábrica.

Até mesmo no auge, a gente teve retorno porque como é uma empresa de família tu acaba fazendo tudo. Tu acaba fazendo mais do que uma pessoa normal que vai trabalhar de empregado. Tu tem quatro, cinco, seis funções [...] Eu sempre fiz coisas aqui que ninguém mais faria. Tu não imagina tudo que eu fiz, carreguei sacola, arrumei resistência, participava de reunião de sindicato com o Sérgio, desde coisas administrativas até coisas mais manuais.

Quando Marcos começou a trabalhar na fábrica, a Rebis estava em crescimento até, aproximadamente, o final da década de 1980 e início de 1990 quando, na opinião de Marcos e Sérgio, a abertura à importação de produtos no Brasil trouxe mercadorias chinesas, o que prejudicou as vendas da Rebis. Uma das implicações disso no presente é o direcionamento das vendas para antiquários, de forma a reclassificar as estatuetas como um produto "antigo" e, portanto, mais valioso. Segundo Simmel (2006), o apreço pelo antigo é o que justificaria a existência de algo mais valioso, de modo que a reclassificação das estatuetas é uma das formas de continuar a existência da empresa.

Não sei se saturou, o pessoal deixava de comprar. É como hoje, parou de comprar as estatueta. Quem sabe daqui a uns quatro, cinco ano não volta tudo de novo. Mas não tem mais... aquele restinho que eu vou ter, vou dobrar o preço.

Ao mesmo tempo em que fazem referência ao "tempo de auge", as memórias são trabalhadas de modo a pensar em um projeto (Schutz, 2012) associado ao campo de possibilidades (Velho, 2003) que existe para a empresa e, portanto, para os indivíduos que fazem parte de Rebis. Cabe notar que esse projeto não se restringe a quem hoje trabalha na Rebis, mas também àqueles que direta ou indiretamente são influenciados pelas decisões do passado e do presente. Portanto, na rede de significados (Geertz, 2008) que compõe suas biografias, está também imbricada a família que é parte constituinte da história do trabalho e serve como um quadro de referência das memórias (Halbwachs, 2006). Diz Sérgio em entrevista:

Tinha dia que eu levava quarenta nota fiscal pra arrumar em casa. Sabe porque minha esposa tá atacada da coluna? Porque ela chamava os guri pra ajudar a pegar as caixa, acho que eles não vinham, aí ela pegava aquelas caixa, ela sozinha. Ela sempre foi muito ligeirinha. Uns dez ano depois da gente casar a fábrica começou a funcionar e ela teve que vim e nós tocamos sempre. Eu, ela, e o Marcos entrou aqui 
tinha doze anos. Marcos tá com quarenta e cinco e nunca nós discutimos. Nunca um olhou atravessado pro outro, entende? Era sempre aquele respeito, porque o Marcos me considera como um pai.

[...] Quando dava uma bronca, minha esposa sempre tentava contornar. E quando ela não conseguia contornar, mandava pra mim. Ela ficou aqui até mais ou menos 2000, que é quando escasseou, escasseou e ela foi embora. Mas aí em 1980 eu tirei o Marcos lá dos fundos e botei ele nas embalagens junto com ela pra conferir a qualidade. Marcos como era bom de olho, não deixava passar.... Carol, eu fazia três forno por semana, doze forno por mês [Sérgio passou a fazer contas com a lapiseira em um papel no meio da entrevista e continuou a falar depois de vários segundos em silêncio fazendo contas]. Olha Carol, chegava a faturar uns sessenta mil naquela época e faz uns oito ano que eu não altero os preço.

[...] E essa é uma das razões que a gente tá liquidando isso aqui. A crise pegou, eu já to há quase quinze ano desde que fizeram o Plano Collor, o livre comércio Europeu, na América Latina. E foi ali, nos anos 90, 2000... É, Carol, claro, foi ali, porque começou a entrar mercadoria, esses de um pila da China, aquelas bailarina porcariazinha. Aí eles reclamam que eu boto dez, vinte, trinta a mais no preço. Mas é que meu trabalho é assim, o deles não.

O que está visível nas narrativas da memória é a característica de sociedades complexas moderno-contemporâneas cuja natureza "está indissoluvelmente associada ao mercado internacional cada vez mais onipresente" (Velho, 2003, p. 38). Não importa necessariamente a precisão das datas e dos planos macroeconômicos que o Brasil viveu em determinada época, mas o fato de que estes planos e a interação que ele acarreta diminuindo as fronteiras entre Estados-Nação - estão presentes nas falas dos sujeitos. Essa problemática está presente, portanto, nas biografias e trajetórias individuais (Velho, 2003; 2006) e, no caso da Rebis, é ressaltado o caráter definidor dessa onipresença na trajetória coletiva dos sujeitos.

A trajetória da Rebis que é também, de certo modo, uma trajetória dos objetos ${ }^{12}$ mostra um processo de mercadorização e desmercadorização das estatuetas, a exemplo das teorizações de Kopytoff (1986) sobre a entrada e saída de algum produto no mercado. A "mercadorização" corresponde ao início das vendas no início da década de 1960, enquanto que a "desmercadorização" das estatuetas ocorre a partir da década de 1990, quando Marcos e Sérgio resolvem reduzir a produção de porcelanas e iniciar a produção de cerâmica ${ }^{13}$ como uma forma de continuar o trabalho da Rebis. Marcos relata em entrevista o início desse novo trabalho:

\footnotetext{
${ }^{12}$ A trajetória dos objetos é pensada à luz da noção de "vida social das coisas" de Appadurai (1986).

13 As peças de cerâmica produzidas pela Rebis são, principalmente, frutas de vários tipos e tamanhos distribuídas às lojas e redes de supermercados.
} 
Tava começando a surgir as frutas no mercado e nas lojas de presente de cerâmica. Aí nós fomos nessa feira e tinha uma fábrica grande que tava fazendo esses produtos de cerâmica, mas o valor deles no mercado era o mais alto. E aí a gente viu que poderia fazer produtos de cerâmica com um preço que desse pra concorrer. Só que como é um produto todo novo que a gente tava fazendo, a formulação da massa que a gente conseguiu, só que tinha a parte da pintura. Então a gente foi descobrindo tintas e a maneira de pintar. Aí eu, Sérgio, Paulo a gente ia se informar. Aí começou a fazer as maçãs. Maçãs, peras, todos os tipos de frutas, mas o que vendia naquela época mesmo era a maçã. Sempre foi as maçãs, foram o forte das frutas. Então, começamos a produzir. Começamos a fazer as matrizes, fazer as formas, já começamos a fazer as frutas e ia atrás de cliente. No início começou algumas coisas a dar problema, problema de verniz, não conseguia a informação correta.

O início da produção de cerâmica foi acompanhado da redução da produção de estatuetas de porcelana, por aproximadamente dez anos, até o momento em que as cerâmicas também não eram mais vendidas. Com a redução da produção de cerâmica, Marcos e Sérgio retomaram a escassa produção de estatuetas de porcelana que perdura até os dias de hoje.

Os processos simultâneos de "mercadorização" e "desmercadorização" das estatuetas e das cerâmicas são ressignificados nas narrativas de Marcos e Sérgio a partir menções ao mercado internacional e à China como principal culpado da derrocada da Rebis. No momento dos acontecimentos passados, Marcos e Sérgio não viam a presença do fator "internacional" no cotidiano da empresa; essa presença somente pôde ser vista em retrospectiva, a partir de um trabalho da memória (Bosi, 1994). Também Dona Eva pontua em sua entrevista a principal razão da derrocada da Rebis: "Por causa dessa....em função da China. Tem muito material da China pra vender. Coisas baratas, e o povão quer coisas baratas. Então deu queda né? Assustador.”

Como reitera Bosi (1994), as lembranças grupais se apoiam umas nas outras, tal qual ocorre com a explicação criada sobre a razão da crise da empresa. O convívio em grupo e o partilhar de um determinado cotidiano de trabalho acabam produzindo esquemas narrativos muito semelhantes usados para explicar determinadas escolhas. Não somente a ressignificação sobre as razões pelas quais a empresa tomou este rumo está em curso com o trabalho da memória, como também um entendimento sobre práticas cotidianas de trabalho que foram sendo modificadas ao longo do tempo, como demonstra a fala de Dona Eva em entrevista:

Mudou, mudou porque são várias peças num dia só pra ti pintar e antes era, por exemplo, pegava uma peça, era aquele tanto só daquela peça e pintava aquela quantidade toda. E com variedade, demora mais, rouba mais o tempo. São várias 
peças junto diferentes [atualmente]. O cabelo é duma cor, a roupa é o outro, aí tem que tá trocando os pincéis e as cores também. Antes a gente pegava um monte, tipo trinta e quarenta peça duma só e pintava. Pegava aquela prática e ia.

A produção de diferentes tipos de peças - entre porcelanas e cerâmicas - implicou uma reordenação das práticas cotidianas (Certeau, 2002), imbricadas na memória de um savoir-faire narrado no presente. "Pra quem pinta porcelana, pintar cerâmica é uma desgraça, é uma desgraça, o processo muda todo, a tinta muda. Eu tinha uma pistola que eu tentava pintar que era na tentativa e erro, tentando se informar com as pessoas", dizia Marcos enquanto caminhávamos pela fábrica que constantemente o fazia lembrar-se de determinadas situações.

Cada elemento na fábrica, cada espaço e cada peça remontam lembranças sobre um tempo diferente que é retrabalhado no momento vivido, como o ressalta Halbwachs (2006), na medida em que este autor sustenta que as lembranças podem ser provocadas por aspectos externos, como o espaço, um grupo ou, por exemplo, a família. No âmbito da fábrica, o próprio espaço é uma fonte de rememorações constantes, quando Marcos mostra-me os espaços e rememora situações à medida que traça percursos na fábrica.

\begin{abstract}
Aí dava umas brigas aqui dentro. Porque acontecia que as meninas tavam aqui ${ }^{\mathbf{1 4}}$ nas formas e elas dependiam que chegasse a massa pronta pra fazer a peça. Aí não chegava nunca, porque dava algum erro lá na massa com os homens. Elas também ganhavam um adicional por trabalhar ali nas formas. Aí elas brigavam com os caras porque não vinha a massa, mas muitas vezes não era culpa deles. Imagina era só mulher aqui pintando e fazendo as bonecas, então elas conversavam sobre tudo, da família, da vida, e tal. Às vezes brigavam, mas nunca dava briga feia. Era muito legal, sempre tinha um monte de gente conversando. E hoje ainda algumas vêm aí pra comemorar aniversário, tomar chá, né Eva?
\end{abstract}

Este excerto foi registrado com auxílio do gravador, quando Marcos concedia sua entrevista e resolveu ir ao espaço da fábrica para mostrar-me algo. Ao mesmo tempo em que caminhávamos pela fábrica, Marcos interagia também com Dona Eva, que confirmou e complementou: "É como uma família aqui né, a gente passa mais tempo aqui que com a nossa própria família" - e sorriu enquanto continuava pintando uma de suas peças. Continuou ele em entrevista:

\footnotetext{
14 “Aqui” e "lá" são grifos para explicitar que durante o discurso, Marcos faz referência gestual aos espaços da fábrica onde determinadas práticas eram conduzidas.
} 
Tem uma relação das pessoas aqui que é bem diferente de outras empresas. Aqui teve funcionário que trabalhou muito tempo e trouxe a família inteira pra trabalhar. Teve uma pessoa da casa ao lado da empresa que vieram as quatro irmãs, e assim acontecia aqui no bairro. Depois veio o pai e o irmão pra ajudar a construir o prédio. Tinha famílias inteiras que trabalhavam aqui por bastante tempo. É diferente de uma empresa que tu tá ali uns dois anos e não sabe o que vai acontecer contigo. Eu vejo isso de conversar com as outras pessoas.

Aproximadamente, uma vez por ano, na ocasião do aniversário das funcionárias que saíram por último da Rebis, ocorrem reuniões no espaço da fábrica para confraternizar. A importância desse fato reside no tipo de relação que as pessoas teriam criado umas com as outras a partir de um convívio diário de trabalho, entendida por Marcos como algo do passado da Rebis e como uma qualidade que hoje não é mais possível de ser sustentada, mas que, de certa forma, perdura no espaço da fábrica uma vez que algumas das relações estabelecidas ali continuam em datas comemorativas específicas.

Os aspectos como "o espaço" e "as datas comemorativas", a exemplo do que diz Halbwachs (2006), são elementos que reordenam as memórias dos indivíduos e, neste caso específico, reordenam as memórias do trabalho uma vez que a percepção de Marcos sobre a diferente relação das pessoas no âmbito da fábrica é vista em retrospectiva à luz das relações de trabalho atuais. No passado, talvez, tais comemorações e usos dos espaços de trabalho não fossem notados como uma qualidade intrínseca da Rebis.

\section{O trabalho nos dias atuais e a expectativa de futuro}

Dado que nas visitas que fiz à fábrica, Marcos e Sérgio diziam-me que não havia mais o que fazer para manter a fábrica funcionando, e que não havia mais por que continuar produzindo, questionei em entrevistas que atividades eles fazem quando vão atualmente à fábrica. Na visão de Dona Eva, o trabalho de Sérgio e Marcos atualmente se resume a recuperar clientes antigos:

Ah, eles ficam tentando. Ligam pra um, ligam pra outro. Pros freguês que eles sempre vendiam. Ficam ligando pros clientes deles. Todos os dias. E o Marcos sai também, vai fazer uma entrega. Aqui por perto.... Shopping e pra essas coisas assim. 
Questionei também Sérgio, em sua entrevista, sobre o que eles continuam fazendo hoje em dia, ao que ele respondeu que o trabalho atual se resume a tentar acabar com a enorme quantidade de matéria-prima que restou. Entretanto, Marcos compra ainda massa de porcelana para produção de novas estatuetas, o que demonstra que não apenas a tentativa de finalizar o que resta, mas produzir novas estatuetas para guardar.

Resto de matéria prima, resto daquelas estatuetas que tem que arrumar, tem que queimar, esmaltar. Mas, novo novo novo não. O Marcos andou queimando ${ }^{15}$ umas aí, umas espanhola, com a Cristina ele fez. Tá vendo aquele casal 42 lá, o mais bonito que eu tenho? Quero ver se eu peço pro Marcos fundir uns quatro ou cinco daqueles que eu vou guardar.

Marcos, em uma de minhas visitas à fábrica, disse: "Enquanto tiver material, a gente continua produzindo" e que quando o prédio for vendido, a Rebis fechará definitivamente. Entretanto, algumas ofertas de compra do prédio já foram realizadas, porém, Sérgio não as aceitou, alegando que o prédio vale mais do que a oferta feita pelas imobiliárias da cidade. Nesse vai-e-vem de diálogos, entre entrevistas e visitas, questiono-me se as recusas às propostas de venda do prédio não são formas de permanecer no espaço e, portanto, na continuidade de um estilo de vida (Velho, 2003).

São relatos de certo modo contraditórios, entrelaçados e $\operatorname{confusos}^{16}$ que demonstram a expectativa de voltar a produzir mais e continuar vendendo estatuetas da mesma forma que se fazia anteriormente. As memórias de Sérgio e Marcos, principalmente, ao incessantemente retomarem o "trabalho duro" do passado por meio das memórias construídas na narrativa, demonstram uma vontade de que o modo de trabalho de hoje seja semelhante ao modo de trabalho do passado. "Sabe que eu não tenho muito tempo, né, Carol" é uma das falas de Sérgio feitas a mim - anotada em diário de campo - que mostra um tom de urgência e de rapidez característico do trabalho resgatado em suas memórias, mas que hoje não é mais presente dada a conjuntura atual da fábrica.

Em outras palavras, as práticas cotidianas (Certeau, 2002) do trabalho mudaram de tal modo que as memórias sobre o trabalho resgatam justamente esse "tempo de

\footnotetext{
${ }^{15}$ A queima é um dos processos de produção de estatuetas de porcelana, enquanto que "esmaltar" referese a outro processo, posterior à queima.

${ }^{16}$ Isso reforça os escritos de Geertz (2008) no sentido de que, muitas vezes, o que se ouve em campo é confuso, enevoado e que buscar uma definição estanque dos dados que se tem em mãos pode fazer o pesquisador incorrer em más interpretações.
} 
auge" em que não se tinha tempo para nada e em que os membros da família realizavam "de tudo um pouco". Hoje, com a escassa produção de estatuetas, há uma reordenação do cotidiano que se expressa na velocidade do trabalho, mais reduzida mesmo que se faça menção explícita ao "não ter tempo" atualmente.

\begin{abstract}
Não tinha telefone naquela época, era por cartinha. Eu era rápido. Hoje eu cato milho, aí eu botava ali [na máquina de escrever] e "zuuuum", pegava a carta e ia direto. Hoje não, tem que pensar o que eu vou escrever. Mas naquela época, cinquenta anos, sangue novo, ia ligeiro. Tinha cinquenta e poucos anos. Eu trabalhei muito muito muito mesmo. A Rebis hoje é conhecida praticamente no mundo, mas com muito sacrifício e a gente não pôde evoluir muito porque tem a mão de obra.
\end{abstract}

A redução na velocidade do trabalho foi também acompanhada por uma sensação de medo ${ }^{17}$ pela possível perda do trabalho. Dona Eva, em dado momento da entrevista diz sobre o período de transição da Rebis, quando os funcionários passaram a notar o rumo que a empresa estava tomando:

Bá foi horrível né, porque a gente viu a firma praticamente fechando já. E ele botando o pessoal pra rua e a gente ficava apavorado. Foi muito difícil. A gente não sabia o que ia acontecer com a gente no outro dia, se a gente ia ficar ou se a gente ia. Tava tenso.

De um cotidiano de trabalho permeado pela rapidez, para outro caracterizado pela lentidão - de vendas, de produção e de atividades administrativas - e pelas reduções de mão-de-obra, as lembranças são pautadas pela crise de uma forma de sociabilidade (Simmel, 2006), de um estilo de vida (Schutz, 2012; Velho, 2003) que, ao reordenar o cotidiano, reordena também o campo de possibilidades (Velho, 2003) dos sujeitos. Nesses momentos de crise, narrados pelos sujeitos, emerge o papel da família nas escolhas que definem o futuro da Rebis, como relata Sérgio:

A minha filha e a minha mulher já há uns 8 anos já queriam que eu fechasse porque, Carol, eu já botei aqui uns cento e cinquenta mil meu. Decidi sair porque a China e eu....eu com o umbigo também enterrado aqui não querendo ir embora. Tem uns cinquenta e seis anos, cinquenta e sete quase de Rebis, então a gente tem amor por isso. Então, faz dois anos que eu decidi definitivamente. Aí minha mulher dizia, tem

\footnotetext{
${ }^{17}$ Rocha e Eckert (2013), em um artigo sobre as transformações da cidade em condição de crise permeada pela violência, apontam, entre outros aspectos, o papel do medo na paisagem urbana. Tomando como ponto de partida a análise de experiências biográficas, as mudanças do mundo urbano contemporâneo fazem-se ver em diversos âmbitos, não somente nas variações da paisagem urbana, como também de outras formas, no interior de uma empresa, nas inseguranças cotidianas do trabalho e no medo de perder o emprego.
} 
que fechar. Tu tá botando todo teu dinheiro, tem que liquidar. Aí eu indenizei, foi indo, foi indo e... [...] Guria, chegava o representante do nordeste aqui com uma pilha de pedidos, e eu, meu deus o que eu vou fazer com isso, era muita cidade. Hoje, dessas lojinhas, 99,9 fecharam. ${ }^{18}$

Como ressalta Lins de Barros (2006), memória e projeto são aspectos indissociáveis de uma biografia, e, à medida que se trabalha a memória, são revistos projetos passados que hoje abrem ou fecham possibilidades. Disse-me Marcos em entrevista: "Não sei se seria melhor se eu tivesse seguido uma carreira diferente. Lógico que a gente só pode dizer essas coisas quando já passou tudo. [...] Mas, eu não posso deixar ele aqui sozinho".

A noção de projeto de Schutz (2012), portanto, é interessante como uma possível forma de analisar o que ocorre nesse contexto juntamente da noção de "campo de possibilidade" de Velho (2003). A família que trabalhou na fábrica, que compartilha do espaço e que também usufruiu o "tempo de auge” da fábrica, é em grande medida quem está presente nas escolhas que definem o rumo desses indivíduos; não ela sozinha - a família - como também seu estilo de vida, seus medos e suas expectativas. O campo de possibilidades, portanto, está entrelaçado à rede de significados (Geertz, 2008) que não é produto de um indivíduo, mas que "expressa a existência e a pressão de uma sociedade que nos precedem e englobam" (Velho, 2006, p. 49).

Então, tinha.... eu via perspectiva de futuro e acabei continu....continuando aqui, eu e o Sérgio. E tem toda essa história de anos e tu vai ficando e a família. Tu até pensa em fazer outro negócio, mas naquela época tu não tinha essa visão que de repente daqui a uns anos esse produto não vai ter continuidade. Então, muitas vezes não parei pra fazer essa análise. Como vivia daqui, vivia bem, era muito trabalho e eu gostava, então, fui dando continuidade e lógico, hoje até tu te arrepende... Mas fazer o que né? Eu já to aqui há trinta e dois anos. To quase me aposentando. Lógico, se tu for olhar pra trás, todo mundo vai dizer isso né, ah, poderia ter feito melhor, poderia ter feito outra coisa, mas será também, né?

O repensar sobre as escolhas é também um repensar sobre seus conhecimentos, na medida em que, uma das preocupações de Marcos é acreditar que ninguém se importa com porcelanas, muito menos com seu trabalho com as estatuetas, tal qual, na obra de

\footnotetext{
${ }^{18}$ Cabe observar um aspecto importante da narrativa de Sérgio que, associada à crise atual, sempre exemplifica contrastes com o "tempo de auge". Ao longo de sua narrativa, as decisões tomadas recentemente são mescladas às memórias da abundância do passado. Ou seja, a narrativa é de tal modo fragmentada que, dificilmente, se completa uma linha de raciocínio: sempre se retorna ao momento anterior, o que demonstra o trabalho da memória em uma circularidade entre passado e presente.
} 
Bosi (1994, p. 24), há a fala de Dona Brites que se questiona “Que me resta ainda? [...] Quem vai querer saber do meu conhecimento em porcelana? Então é um conhecimento que eu tenho, mas que não tenho como usar daqui pra frente."

Somente é possível rememorar com tal julgamento acerca de seus saberes tendo em vista um contexto atual de desvalorização dessa arte de fazer (Certeau, 2002). Entretanto, há a expectativa de recomeço, de que a "trajetória da coisa" volte à mercadorização (Kopytoff, 1986) e que seus saberes sejam novamente valorizados. Concebendo que a memória não é separada de um projeto futuro (Eckert e Rocha, 2009), a continuidade da Rebis se dá pela expectativa de que a conjuntura mude, como fala Marcos em entrevista: "Acho também que o tipo de decoração mudou. Porcelana era o auge naquela época, mas aí a gente viu que as porcelanas não tavam mais vendendo tanto, aí resolvemos partir pra cerâmica. Hoje já não é mais cerâmica, então estamos literalmente sobrevivendo. Depois a gente não sabe o que pode acontecer daqui a 5 anos, né? Pode ser que a porcelana volte. Essas coisas de mercado mudam muito, aí a gente tem aqui um baita estoque".

\section{Reflexões Finais}

Procurei trazer relatos sobre memórias do trabalho que estão situadas em um contexto específico, de uma empresa em processo de falência, vivendo crises que se refletem no diálogo entrevistador-entrevistado, mas que não se restringem ao que está localizado nesta empresa. As vivências de Sérgio, Marcos e Dona Eva fazem parte das transformações que vive a sociedade complexa moderno-contemporânea (Velho, 2003) e que podem ser demonstradas pelas mais diversas nuances. Esta, em específico, referiu-se às memórias do trabalho em uma empresa, calcadas no cotidiano, indissociáveis de um projeto futuro e também permeadas por medos e expectativas que não são somente desses sujeitos em específico.

Os relatos que reiteram diversas vezes o trabalho com as estatuetas, a materialidade dos objetos, sua trajetória social ou a venda em si mesma - e, portanto, os valores monetários decorrentes das vendas, diversas vezes citadas por Sérgio - não podem ser entendidos em si mesmos, uma vez que demonstram a vontade de continuar 
o trabalho e de justificar a permanência em um espaço que é, ele mesmo, motivo da continuidade.

O que pude ver são memórias que justificam a permanência no espaço de trabalho de forma que Marcos, Sérgio e Dona Eva continuem indo todos os dias à fábrica, mesmo em momentos em que não há muitas atividades para fazer. São memórias de família, de compras, vendas, de relações entre pessoas que buscam manter uma forma de sociabilidade (Simmel, 2006) e resgate de um período social em específico comprometidos pelo fechamento da fábrica.

De um ponto de vista racional-instrumental, a fábrica não teria mais razão de existir uma vez que seu objetivo lucrativo não se cumpre. Contudo, o simples fato de existir ainda - mesmo com todas as dificuldades atuais - mostra que a continuidade da fábrica e, portanto, do trabalho com suas práticas modificadas representa também a continuidade de uma forma de viver e trabalhar que está impressa nas memórias contadas por esses sujeitos. Assim sendo, o que está em discussão é a permanência do trabalho cujas práticas se alteram conforme as circunstâncias que vivem as pessoas que partilham desse espaço diariamente.

Não é possível afirmar o rumo que o estilo de vida, a sociabilidade e a família envolvida na empresa tomarão a partir do fechamento total da fábrica, uma vez que este fato ainda não ocorreu. Porém, entendendo que a sociabilidade não cessa de se refazer com as transformações do cotidiano, ela assumirá outras formas com o encerramento total das atividades da fábrica.

Entretanto, mesmo que as atividades se encerrem, o trabalho cesse e as formas de sociabilidade se modifiquem, suas vidas, escolhas passadas e futuras estarão intrinsecamente relacionadas às estatuetas de porcelana, permeando continuamente a memória do trabalho, não somente nas narrativas, mas também na própria materialidade das estatuetas que, segundo Sérgio e Marcos, serão guardadas como recordação de um tempo áureo.

Sendo assim, também quis demonstrar que as memórias do trabalho na Rebis não podem ser separadas da trajetória que as coisas traçam de uma forma ampla, entrando e saindo de um circuito de consumo, o que as caracteriza como objetos biográficos, na medida em que as pessoas contam e recontam sua vida de trabalho por meio das histórias que viveram com esses objetos. 


\section{Referências}

APPADURAI, A. The Social Life of Things. Cambridge: Cambridge University Press, 1986.

BENJAMIN, W. Magia e Técnica, Arte e Política: ensaios sobre literatura e história da cultura. São Paulo: Brasiliense, 2012.

BOSI, E. Memória e Sociedade: lembranças de velhos. São Paulo: Companhia das Letras, 1994.

CERTEAU, M. de. A Invenção do Cotidiano. Petrópolis: Vozes, 2002.

ECKERT, C. Memória e Trabalho: etnografia da duração de uma comunidade de mineiros de carvão. Curitiba: Appris, 2012.

ECKERT, C. e ROCHA, A.L.C.da. Etnografia da Duração: estudos de memória coletiva. In: Memória e Cultura: perspectivas transdisciplinares. Canoas: Salles, 2009.

GEERTZ, C. A Interpretação das Culturas. Rio de Janeiro: LTC, 2008.

HALBWACHS, M. A Memória Coletiva. São Paulo: Centauro 2006.

HOSKINS, J. Biographical Objects: how things tell the stories of people's life. New York: Routledge, 1998.

KOPYTOFF, I. The cultural biography of things: commoditization as process. In: APPADURAI, A. The Social Life of Things. Cambridge: Cambridge University Press, 1986.

LINS DE BARROS, M. M. Memória, Experiência e Narrativa. Iluminuras, Porto Alegre, v.12, n. 29, p. 4-17, jul./dez. 2011.

LINS DE BARROS, M.M. Trajetória dos Estudos de Velhice no Brasil. Sociologia, Problemas e Práticas, n. ${ }^{\circ}$ 52, 2006, pp. 109-132.

PORTO ALEGRE QUEM DIRIA. Disponível em: http://www.portoalegrequemdiria.com.br/. Acesso em: 09 de Março de 2013.

RICOEUR, P. A Marca do Passado. História da Historiografia. Ouro Preto, n. 10, dezembro, 2012, p. 329-349.

ROCHA, A.L.C. da; ECKERT, C. "A cidade com qualidade": estudo de memória e esquecimento sobre medo e crise na cidade de Porto Alegre. In: ROCHA, A.L.C. da; ECKERT, C. Antropologia Da e Na Cidade: interpretações sobre as formas de vida urbana. Porto Alegre: Marcavisual, 2013.

SCHUTZ, A. Sobre Fenomenologia e Relações Sociais. Petrópolis: Vozes, 2012. 
SIMMEL, G. Questões Fundamentais da Sociologia. Rio de Janeiro: Jorge Zahar, 2006.

SIMMEL, G. The Philosophy of Money. New York: Routledge, 2004.

VELHO, G. Projeto e Metamorfose. Rio de Janeiro: Jorge Zahar, 2003.

VELHO, G. Subjetividade e Sociedade: uma experiência de geração. Rio de Janeiro: Jorge Zahar, 2006.

Recebido em:26/07/2013

Aprovado em: 12/08/2013 